\title{
Study on the Combustion Products of Dimethyl Silicone Oil as Anode Materials for Lithium Ion Batteries
}

\author{
Keqiang Ding ${ }^{1,3^{*},}$ Xiaomi Shi ${ }^{1}$, Chenxue Li $^{1}$, Xiaojing Gao ${ }^{1}$, Jingwei Han ${ }^{1}$, Hui Wang ${ }^{3}$, \\ Hongmin Dou, Junqing Pan ${ }^{2, *}$ \\ ${ }^{1}$ College of Chemistry and Materials Science, Hebei Normal University, Shijiazhuang, Hebei 050024, \\ P.R. China \\ ${ }^{2}$ State Key Laboratory of Chemical Resource Engineering, Beijing University of Chemical \\ Technology, Beijing, 100029, China \\ ${ }^{3}$ Hebei LingDian New Energy Technology Co., Ltd, Tangshan, Hebei, 064200, P.R.China \\ *E-mail: dkeqiang@263.net; jqpan@mail.buct.edu.cn
}

doi: $10.20964 / 2018.11 .57$

Received: 4 June 2018 / Accepted: 6 August 2018 / Published: 1 October 2018

\begin{abstract}
For the first time, a novel finding, that the combustion products of dimethyl silicone oil can be used as the anode materials for lithium ion batteries (LIBs), was reported in this work. Namely, a proper amount of dimethyl silicone oil was burned at $800^{\circ} \mathrm{C}$ in a muffle furnace for $2 \mathrm{~h}$, leading to the formation of two kinds of products, namely, white particles (sample a) and black particles (sample b). And then, sample a was thoroughly mixed with sample $b$ at the mass ratio of $1: 1$ generating a new kind of material (sample c). All prepared samples were respectively characterized by XRD, SEM and XPS. No typical diffraction peaks were found in all resultant XRD patterns which strongly indicated that all prepared samples were amorphous in nature. SEM images revealed that many large spherical particles were prepared in sample $a$, and sample $b$ contained many irregular large blocky particles. The results of galvanostatic charge and discharge experiments indicated that the initial discharge capacities of sample $\mathrm{a}, \mathrm{b}$ and $\mathrm{c}$ at $100 \mathrm{~mA} \mathrm{~g}^{-1}$ were 43,41 and $68 \mathrm{mAh} \mathrm{g}^{-1}$, respectively. Interestingly, after 50 cycles, the discharge capacities at $100 \mathrm{~mA} \mathrm{~g}^{-1}$ of sample a, b and c were 30,48 and $44 \mathrm{mAh} \mathrm{g}^{-1}$, respectively. Summarily, a novel way, i.e., burning the Si-contained organic substances to prepare anode materials for LIBs, was developed in this work, which was very meaningful to the development of LIBs anode materials.
\end{abstract}

Keywords: dimethyl silicone oil; burning; anode materials; lithium ions battery

\section{FULL TEXT}


(C) 2018 The Authors. Published by ESG (www.electrochemsci.org). This article is an open access article distributed under the terms and conditions of the Creative Commons Attribution license (http://creativecommons.org/licenses/by/4.0/). 